\title{
LA PENALIZACIÓN DE LOS MIGRANTES: IRREGULARIDAD Y CÁRCEL EN LA CONSTRUCCIÓN DEL ESTADO NEOLIBERAL*
}

\section{THE PENALIZATION OF MIGRANTS: \\ IRREGULARITY AND PRISON IN THE CONSTRUCTION OF THE NEOLIBERAL STATE}

IGNACIO GONZÁLEZ SÁNCHEZ ${ }^{\star \star}$

Resumen: En el presente artículo se analizan los procesos punitivos que afectan de una manera notable a las personas extranjeras en España. Tras una breve contextualización del proceso migratorio, y de su problematización en términos relacionados con la inseguridad y la delincuencia, se presta atención a dos formas de penalización: la administrativa, vinculada a las leyes de extranjería, y la penal, reforzada por la situación precaria de estos colectivos. Posteriormente se analizan sus efectos materiales -relacionados con el mercado laboral-, simbólicos -en las categorizaciones sociales- y disciplinarios -en la conformación de subjetividades-. Se defiende la pertinencia de estudiar los procesos de penalización para vislumbrar dinámicas sociales más amplias y la pertinencia de dar mayor importancia a estos procesos en los estudios sobre las personas migrantes.

El presente trabajo se enmarca dentro de los proyectos de investigación DER2015-64403-P y DER2014-52674-R, financiados por el Ministerio de Economía y Competitividad.

** Departament de Dret Pùblic, Facultat de Dret, Universitat de Girona, Campus de Montilivi, c/ de la Universitat de Girona, 12, 17071 Girona. Nacho.gonzalez.sanchez@gmail.com 
Palabras clave: castigo, sistema penal, población migrante, deportabilidad, cárcel.

Abstract: In this paper the punitive processes affecting foreigners in Spain are analyzed. After a brief contextualization of the migratory process, and its problematization in terminology related to insecurity and crime, attention is paid to two ways of penalization: the administrative one, linked with laws for foreigners, and the penal one, reinforced by the precarious situation of these collectives. Later, an analysisi of their effects of the material — related to the labor market-, symbolic - in social categorizations - and disciplinary -in the conformation of subjectivities-is provided. The pertinence of studying processes of penalization to discern broader social dynamics and the pertince of giving more importance to these processes in studies about migrant populations is here proposed.

Keywords: punishment, penal system, migrant population, deportability, prison.

En las últimas dos décadas la sociología española ha desarrollado un buen número de estudios explorando las distintas facetas del fenómeno migratorio. De los muchos aspectos tratados, uno de lo que menos atención ha recibido ha sido el relacionado con los procesos penales. En este artículo se toma por objeto principal el sistema de castigo, y cómo este opera sobre la población migrante.

Dada la selectividad con la que operan los sistemas penales, estudiar este proceso es interesante por dos cuestiones. La primera, relacionada con el estudio del castigo, es que los grupos sistemáticamente penalizados sirven como indicador de características de la sociedad. Por ejemplo, en la España de los 80, la figura del drogodependiente puede ser identificada como la categoría en la que confluían distintos aspectos centrales en los procesos de inclusión social de aquella época. Así, de modo somero, se puede ver cómo afectaba a una juventud para la que no había sitio en el mercado laboral, provenían de barrios obreros y se refugiaban en las drogas. En décadas anteriores, el grupo por excelencia era el de la población gitana, demonizados política y mediáticamente y perseguidos por la Guardia Civil, y sobre los que todavía pesa un enorme estigma. La segunda, porque la presencia casi diaria de 
los mecanismos penales hace que sean muy importantes para los estudios cualitativos sobre la personas migrantes, especialmente a la hora de configurar sus rutinas diarias y en la conformación del significado social de la inmigración.

Aunque el volumen de trabajos que estudian la relación entre inmigración y sistema penal son aún escasos en España, y los pocos datos disponibles son insuficientes para hacer un análisis en detalle (Monclús Masó, 2006: 159), varios autores han señalado que las personas migrantes han pasado a ser un grupo central para el sistema penal y los procesos de penalización en España durante las últimas dos décadas (Brandariz y Fernández, 2010: 273-274).

A continuación se contextualizará brevemente la llegada de migrantes durante las últimas décadas, con especial atención a su construcción político-mediática, así como la existencia de unas leyes de extranjería y su papel en la inclusión subordinada a la que pueden optar muchos migrantes. Posteriormente, se detallarán los procesos de penalización mediante la vía administrativa y la deportabilidad y la vía penal y la cárcel. Para concluir, se analizarán los efectos que tiene la penalización de los migrantes.

\section{DE UN PAÍS DE EMIGRANTES A UNO DE INMIGRANTES: EL PÁNICO MORAL DE LOS INVASORES PELIGROSOS}

La actual penalización del colectivo migrante se entiende mejor en el contexto histórico y político de las últimas décadas. Los movimientos migratorios no son nuevos en España, y de hecho han formado una parte fundamental en la constitución de la sociedad, como en casi todos los países. No obstante, sí se han producido recientemente dos cambios importantes: por un lado, España ha pasado en un período relativamente breve de tiempo de ser emisor de migrantes a ser receptor comenzando a tener un saldo positivo de migraciones en 1973, hasta 1995 multiplicó por tres el número de extranjeros residentes en España y por siete desde entonces hasta 2007. En 2001 había ya más extranjeros residiendo en España que españoles residiendo en el extranjero (Colectivo IOE, 2008: 30). Por otro lado, el volumen de la inmigración, que en el año 2000 suponía el $0,9 \%$ de la población residente en España y que en diez años había 
pasado a conformar el 12\%1. Para el período que va desde 1990 hasta 2005, España fue el país del mundo que más aumentó, en términos relativos, su población inmigrada (Aparicio Wilhelmi, 2010: 57). Es también muy destacable que, hasta principios de los 90, la mayoría de los inmigrantes en España eran comunitarios, de elevada edad y baja actividad laboral (Izquierdo, 1996: 135; para todo el proceso, ver Cachón, 2002, 2003).

El hecho de que haya un cambio en la dirección de los procesos migratorios y un fuerte incremento en su volumen no explica de por sí la penalización de los migrantes ni su asociación con la delincuencia o con la competencia por unos puestos de trabajo. Esta asociación es contingente y se construye social y políticamente. Una parte importante de la literatura ha prestado atención a estos procesos, y en especial a la vinculación entre inmigración y delincuencia en los medios de comunicación.

En general, se ha denunciado que los medios de comunicación son los grandes culpables de esta representación conflictiva de la llegada de inmigración a España (Baratta, 2006: 271), aunque hay algunas diferencias según su línea editorial (Igartua, Muñiz y Cheng, 2005: 175). Se ha señalado que el tratamiento que hacen del fenómeno migratorio está sesgado por cuanto la mayoría de las noticias al respecto tienen un tono de alarma; señalan el origen extranjero del delincuente; o emplean categorizaciones simples que refuerzan la imagen del extranjero como otro distinto (ver Martínez Lirola, 2008; Igartua, Muñiz y Cheng, 2005; Villalobos Molina, 2005). No obstante, conviene recordar que la gran mayoría de la información, los casos y la forma de contarlos, proviene de fuentes oficiales (Rechea Alberola, et al. 2005: 12; Baratta, 2006: 266-268) y que esa definición primaria del hecho noticiable (empezando por que unos hechos sean noticia y otros no) es de vital importancia. Es decir, que el hecho de que la inmigración aparezca asociada a la delincuencia es causado muchas veces por la propia policía y su gabinete de prensa, el cual convierte en noticiables unos sucesos y otros no, y destaca la nacionalidad del infractor o no, entre otros

1 Los datos sobre extranjeros en España siempre han de ser tomados como aproximados, debido a la dificultad de medir el volumen de las migraciones, a su temporalidad y a la existencia de inmigración que se da al margen de instancias oficiales. A pesar de que el Padrón sigue siendo el mejor indicador, se trata de datos aproximados e importa más que se trate de un incremento cercano al $1.000 \%$ que a unos decimales arriba o abajo. Ver también Reher y Requena, 2009: 11-15. 
aspectos importantes. Dos factores parecen importantes para explicar la importancia que se le da a las fuentes oficiales: el ahorro que le supone a una empresa de comunicación no tener que producir la información de primera mano, y la credibilidad y autoridad de las instancias oficiales (en especial las vinculadas con la ley y el orden) derivadas de su capital simbólico (Villalobos Molina, 2005: 157).

Hay que tener en cuenta que el discurso político que identifica a los inmigrantes con una fuente de inseguridad parece haber precedido a la cobertura mediática (Zuloaga, 2011: 36-37), por lo que parece más acertado referirse a un discurso político mediatizado que a un discurso mediático. Se ha señalado la existencia de una relación recíproca entre la construcción política y mediática de los problemas (Hall, et al., 1978: 76), aunque se pueda cuestionar que las dos partes tengan la misma importancia. Además, no hay que olvidar la contribución a la construcción simbólica de los grupos que tiene de por sí la propia legislación. Por ejemplo, las leyes de extranjería presentan al migrante como una figura especial sobre la que es necesario actuar de manera distinta, excepcional, y como tal comunican cierta peligrosidad de este colectivo.

La inmigración ha estado asociada a la delincuencia, pero en un nivel más profundo se ha vinculado a la cultura. Así, la inseguridad ha tendido a presentarse como la consecuencia (automática) de una falta de adaptación cultural ${ }^{2}$. Como se verá, más que una adaptación cultural, lo que se les exige es una adaptación a las demandas y condiciones del mercado de trabajo. Así, se pasa a representar un problema de clase, vinculado con la dificultad de integrarse en una sociedad desde los estratos más bajos de la misma y sin gozar de derechos básicos para la integración, como un problema cultural, presentando continuidades con la tradición de equiparar las clases bajas con las clases peligrosas (Delgado, 2006: 14; Sayad, [1999]: 403). En definitiva, se despolitiza la cuestión mediante su penalización y su encuadramiento en un discurso técnico de mantenimiento del orden (Wacquant, 2006: 97). Al igual que en EE.UU. los temas relacionados con la delincuencia fueron importantes para reconstruir la visión de los pobres (Beckett, 1997: 40), en España parece que la cuestión de la inseguridad ha contribuido de manera importante a la visión de los inmigrantes.

2 Interpretación ésta que, de manera más general, suele estar más relacionada con la llegada de un grupo forastero a un territorio más que con las características propias ese grupo. Ver Elias, [1994]: 222-223. 
Los procesos por los que periódicamente aparecen «olas de criminalidad» (Erikson, 1966: 69) o «pánicos morales» (Cohen, [1972]: 19) son fenómenos sociales bastante complejos y que están estrechamente relacionados con la reacción a un determinado fenómeno, más que con las características del fenómeno mismo. La reacción de las autoridades, y su construcción mediática, son fundamentales para la significación e interpretación de ese fenómeno, algo que es constitutivo del mismo. Poco importa que la mayoría de la evidencia apunte a que los inmigrantes no parecen cometer más delitos que los nacionales que se encuentran en similares situaciones sociales (Serrano Gómez et al., 2007: 106117). Este dato sería sólo un elemento más en la conformación de «la inmigración» en España, y no necesariamente el más importante. Otro elemento que ha sido determinante en la conformación del fenómeno ha sido el ámbito europeo, tanto la creación y consolidación de la Unión Europea, como la inserción de España en ella y la adaptación de algunas de sus políticas a los requisitos de Bruselas.

\section{LA INTEGRACIÓN EN EUROPA: INCLUSIÓN SUBORDINA- DA Y CIUDADANÍA DE SEGUNDA}

La importancia de la Unión Europea se detecta de manera rápida al ver que las leyes de extranjería y el control de las migraciones aparecen directamente ligados al proceso de inserción de España en el espacio europeo. La primera ley de extranjería se aprueba en 1985 como requisito para acceder a la CEE en 1986, y no parece que esté motivada por necesidades nacionales, habida cuenta del bajo volumen de inmigración existente entonces. La posición geográfica de España la convertía en una de las fronteras sur de la Unión Europea, quien ha insistido mucho en el control de entrada de ciudadanos no comunitarios. En 1991, como requisito para la admisión de España en el acuerdo Schengen, se aprobó un decreto que endurecía las condiciones para acceder a España de manera regular (ver González Cámara, 2011: 145-150; para Europa, ver Huysmans, 2000: 753-756). A tal punto ha llegado que el control de las fronteras está definido en términos de control y seguridad, junto al terrorismo, el tráfico de drogas o el crimen organizado (Gil Araújo, 2005; Wacquant, 2006: 92).

Una consecuencia del proceso de construcción de la Unión Europea, y la situación de España en él, ha sido la creación de 
inmigración irregular. La legislación de extranjería, paradójicamente, crea unos sujetos jurídicos que son precisamente los que pretende prohibir (González Cámara, 2011: 150). Esta legislación determina que la situación administrativa regular de un migrante depende de que trabaje. Así, la ciudadanía cercenada a la que pueden acceder los migrantes (de la que prácticamente se excluye la ciudadanía social, y, desde luego, la ciudadanía política [Delgado, 2006: 11; De Giorgi, 2010: 160]) depende de tener un trabajo legal. El hecho de que se hayan creado figuras jurídicas especificas para los extranjeros, y que bastantes derechos no les sean reconocidos, permite hablar de «la creación de un estatus jurídico dual entre ciudadanos y extranjeros» (Silveria Gorski, 2010: 149). Este proceso de cierre ante un grupo que llega es característico de dinámicas de los grupos establecidos para preservar su poder (Elias, [1994]: 227, 239).

La temporalidad y la fragmentación de las vidas laborales en las economías postfordistas traducen esta legalidad de los migrantes en un estatus legal precario, que fácilmente puede llevar de nuevo a la irregularidad. Esta dependencia de un trabajo legal, el que sea, explica en gran medida que las personas migrantes en España ocupen trabajos poco cualificados y que cobren sistemáticamente menos que los españoles por la misma tarea (Calavita, 2003: 403; Cachón, 2003: 260-263) pues el empleador se puede beneficiar de la necesidad legal que tiene este colectivo de trabajar. Las dos voluntades libres que idealmente se reúnen en un contrato (y que rara vez han existido) no tienen cabida legal en este caso: el contrato laboral se firma bajo la amenaza de la Ley de Extranjería.

En resumen, la posibilidad de ser miembros de la ciudadanía para los y las migrantes se basa, no ya en la residencia estable en un territorio, sino en su papel como trabajador o trabajadora. No goza de los mismos derechos que los ciudadanos nacionales pero sí comparte las mismas obligaciones, más la de trabajar. Esta inclusión subordinada pone en marcha el principio de menor elegibilidad (less eligibility), por el cual las personas migrantes se ven ante la disyuntiva de aceptar unos puestos de trabajos muy precarios, con condiciones que los trabajadores nacionales difícilmente aceptarían, o vivir la tensión diaria de ser víctima de una de las muchas y rutinarias redadas racistas que lleva a cabo la policía, y que pueden acabar con un internamiento en un CIE y/o con una eventual expulsión. La idea que subyace, mediante la deportabilidad que ahora se tratará, es que algunos son deportados para que otros no lo sean y trabajen (González Cámara, 2011: 312-313). 


\section{LA PENALIZACIÓN DUAL: DEPORTABILIDAD Y CÁRCEL}

Este epígrafe tiene como objetivo destacar dos de las formas más importantes de penalización que sufren las personas que han inmigrado a España. Por motivos analíticos, se ha creído conveniente distinguir la penalización a través de la cárcel de la que se ejerce a través de la policía, pues los mecanismos y las justificaciones son sustancialmente distintos.

\section{Irregularidad, policía y controles racistas: la deportabilidad como mecanismo de disciplinamiento}

Se va a exponer la penalización de los migrantes a través de la creación de la «inmigración irregular». Se trata de una penalización presente en el día a día (salvo en el caso de internamiento en un CIE). Se lleva a cabo principalmente a través de la policía y del derecho administrativo (aunque prevea medidas, como el internamiento, propias del derecho penal).

A través de las leyes de extranjería aprobadas durante las últimas décadas se ha construido a los migrantes como una categoría de riesgo (De Giorgi, 2006: 133; Brandariz y Fernández, 2010). Esto no quiere decir que haya sido premeditado y, de hecho, estas leyes resultan de múltiples lógicas y contradicciones (González Cámara, 2011: 75). Su articulación como sujetos excepcionales, distintos de los nacionales, así como su gestión a través de mecanismos de control, otrora reservados para conductas ilegales, así parecen indicarlo. De hecho, un efecto simbólico de la distinción entre inmigrantes regulares e irregulares (o en determinados discursos políticos y mediáticos, incorrectamente, «ilegales») es una división y categorización social entre los inmigrantes «buenos» y los «malos». Dado que el criterio para que la situación de una persona migrante sea regular o no es su participación (legal) en el mercado de trabajo, caer de un lado o de otro no es una cuestión ontológica, sino temporal. Es la propia ley la que propicia que sea un estado temporal y que esté lleno de interrupciones, más que intentar controlar la entrada de migrantes (Calavita, 1998: 530; De Giorgi, 2006: 133). No obstante, a través de su vinculación con el sistema penal, algo que en realidad es una

situación administrativa temporal pasa a ser un eje vertebrador de la exclusión o la aceptación social de determinados grupos. 
Hay que tener presente que la mayoría de los migrantes que se encuentran en situación de irregularidad entraron en España de manera legal, ya sea con visado de turista o con permiso de trabajo. Entonces, a pesar de que existe un reforzamiento del control fronterizo, la mayor actividad para detectar la irregularidad se da dentro del propio país, a través de la policía mediante controles de identidad (ver García Añón, 2013) en lo que algunas voces han señalado como un intento de desarrollar fronteras interiores.

Estas prácticas policiales tuvieron trascendencia mediática, debido a la labor de denuncia de distintos colectivos, entre ellos las Brigadas Vecinales de Observación de Derechos Humanos y el Sindicato Unificado de Policía (por motivos bien distintos) en torno a 2008. Este desplazamiento de prácticas de identificación propias de los puestos fronterizos al interior de las ciudades ha tenido importantes efectos materiales y simbólicos. La importancia de la policía en esta forma de penalización, y la discrecionalidad con la que actúan (Monclús Masó, 2006: 160; Silveira Gorski y Rivera Beiras, 2009: 11) han sido objeto de fuerte debate. Cuando la propia denuncia de estas prácticas por parte de los sindicatos de policías salió a la luz, el Ministerio del Interior negó la existencia de las redadas racistas por la propia ilegalidad de las mismas (en un razonamiento circular que pone a prueba la eficacia simbólica del derecho) ${ }^{3}$.

Desde entonces las redadas siguen existiendo, pero sin la visibilidad que antes tenían. Son ahora agentes de paisano quienes las realizan a la salida de las estaciones de metro de barrios con alta proporción de población migrante,. En todo caso, el efecto que estas prácticas introducen en la vida cotidiana de las personas inmigradas es la amenaza constante de identificación, que supone un descrédito y una humillación frente a los vecinos, con posibles efectos estigmatizadores, y la posibilidad real para las personas migrantes en situación irregular de salir a comprar comida (o a buscar trabajo) y acabar encerrada. Sólo en Madrid, en 2010 había unas 300.000 personas en esta situación, en la que el miedo se convierte en una experiencia diaria (Ávila Cantos, 2012: 100, 157).

3 Se establecían, incluso, unas cuotas semanales por comisaría de migrantes irregulares a detener. Así mismo, se recomendaba la detención de marroquíes (curiosamente, también la nacionalidad no española más representada dentro de las cárceles) dada su facilidad económica y política para la deportación. Ver, por ejemplo, El País, 16/02/09. 
Esta superposición de mecanismos de control penales y administrativos sobre la población migrante da un mayor margen de discrecionalidad a la policía y al Gobierno, al menoscabar la tutela judicial efectiva y el derecho de defensa (Silveira Gorski y Rivera Beiras, 2009: 10). Además, el rigor de la medida no es proporcional a la falta cometida. En este sentido, el ejemplo más claro lo supone el internamiento en los Centros de Internamiento de Extranjeros (CIE) (ver, por ejemplo, Martínez Escamilla, 2011). En ellos se encierra a los extranjeros sobre los que se ha dictado una orden de expulsión hasta que ésta se materializa, con un plazo máximo de 60 días. El régimen, a efectos prácticos, es peor que el de los centros penitenciarios regulares, pero además sin ciertas garantías y controles propios del sistema penal. Se priva de libertad a una persona (restricción de un derecho fundamental) por una infracción administrativa, algo que supone una clara vulneración de los principios del Estado de Derecho, y que sugiere que en España se ha creado un subsistema penal administrativo para los extranjeros (Silveira Gorski, 2010: 135-142) en el que además se produce un fraude de etiquetas, al dar un trato penal mediante vía administrativa (Brandariz, 2011: 74).

Como siempre, igual de importante que la ley es su aplicación. Cuando se atiende a los datos, muy pocos migrantes en situación de irregularidad son deportados, y sólo uno de cada dos de los que son internados en los CIE (Fiscalía, 2010: 889). Se expulsa a una pequeña proporción, y se hace de manera selectiva (dependiendo el país de origen, convenios internacionales, coste de la deportación, etc. $)^{4}$. De Genova (2002: 438-439) ha señalado de manera influyente que no se trata tanto de la deportación en sí, sino de la «deportabilidad», entendiendo por ésta la posibilidad de que se sea deportado, o no. En este sentido, se puede interpretar que las políticas de extranjería que crean la «irregularidad» no tienen como objetivo impedir el acceso, sino permitirlo en unas condiciones que favorezcan la explotación laboral, mediante la gestión de los flujos migratorios (De Giorgi, 2006: 120; Brandariz y Fernández, 2010: 284).

Dicho con otras palabras: la existencia de migración irregular y la aplicación de sus sanciones está encaminada a que la población migrante viva en una constante incertidumbre sobre su estatus

4 Una investigación específica sobre las formas que ha adoptado la política de deportaciones en los últimos años, refinando su selectividad, se puede ver en Fernández Bessa, 2015. 
jurídico (regular o irregular) y social (inmigrante bueno o inmigrante malo). Dado que la condición para residir legalmente es la participación en el mercado laboral, la deportabilidad tolera la existencia de migrantes en suelo español, pero bajo la amenaza de la deportación efectiva si no se trabaja. Se produce, al incorporar requisitos específicos para trabajar y restricciones en el acceso a derechos sociales, una inclusión subordinada (De Giorgi, 2010: 156).

\section{La cárcel: gestión de ciudadanos no fordistas}

No obstante, la penalización de este colectivo también alcanza instancias más clásicas del castigo moderno. El rápido y pronunciado incremento de reclusos extranjeros ha sido uno de los cambios más significativos en las prisiones españolas durante los últimos 15 años. La magnitud de este fenómeno es tal que han llegado a ocupar una de cada tres plazas carcelarias. En el siguiente gráfico se puede apreciar la evolución del porcentaje de presos no nacionales:

\section{GRÁFICO 1}

\section{EVOLUCIÓN PORCENTUAL DE LOS PRESOS EXTRANJEROS EN ESPAÑA (1975-2013)}

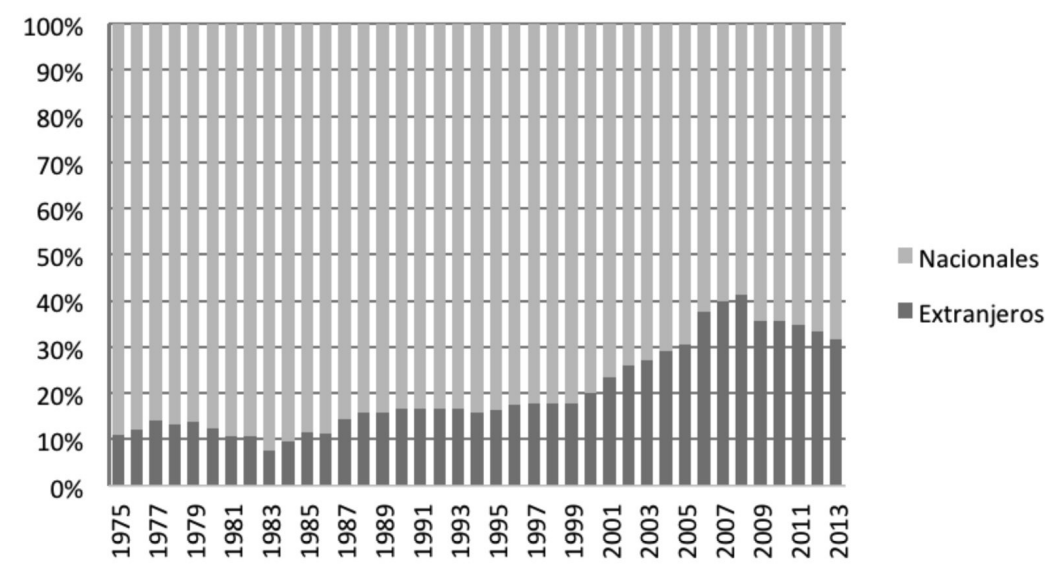

Fuente: elaboración propia a partir de datos de SGIP y de la Generalitat de Cataluña. 
Este incremento de la proporción extranjeros/nacionales no se ha debido a una disminución de presos españoles, sino a un incremento mayor aún de encierro de extranjeros (que han pasado de 7.900 en el año 1999 a 21.116 en 2013, frente a una evolución de 36.278 a 45.559 de presos españoles). En España las posibilidades de que un extranjero acabe en prisión cuadruplican las opciones de los españoles: la tasa de encarcelamiento de los extranjeros en España era, en 2009, de 473 por cada 100.000 habitantes, frente a los 118 por cada 100.000 habitantes de los nacionales. Esta tendencia se da en casi todos los países europeos, aunque no se puede hablar de uniformidad en el proceso debido principalmente a su magnitud, evolución y peso relativo (Delgrande y Aebi, 2010: 142). De igual manera, es difícil hacer generalizaciones sobre un colectivo tan heterogéneo -colectivos, en realidad- y es conveniente prestar atención a las distintas nacionalidades En concreto, las tres nacionalidades más representadas son la marroquí, la rumana y la colombiana ${ }^{5}$, y la diversidad de estos colectivos supone algunas especifidades en sus condiciones de encierro en prisión (ver González Sánchez, 2012: 387-389)

El principal motivo del alto porcentaje de presos extranjeros no parece que sea que efectivamente delincan más, o de manera más grave, sino que cumplen más tiempo efectivo de encierro. Esto se debe a que los criterios aparentemente neutrales para ordenar prisión preventiva y para conceder formas de «libertad» vigilada perjudican sistemáticamente al conjunto de extranjeros. En concreto, las personas extranjeras son enviadas en mayor proporción a prisión preventiva (por lo que entran antes en la cárcel) y se les conceden menos libertades condicionales, prolongando así su estancia en prisión a igualdad de condena con un nacional (Delgrande y Aebi, 2010: 143; García España, 2007: 108; Monclús Masó, 2006: 192; García, Becerra y Aguilar, 2012: 101;).

\footnotetext{
5 Desafortunadamente no existen muchos datos al respecto. Los informes de SGIP dejaron de publicar los datos desagregados por nacionalidad. Los últimos datos que hay son los publicados por el Anuario Estadístico del Ministerio del Interior de 2012, de dudosa fiabilidad, habida cuenta de que se computan dos veces a los ciudadanos de la UE (primero como cada país, y luego en una categoría conjunta en la que se suman todos los países miembros y se mete todo en un total del 100\%). Sólo se recogen 6 nacionalidades extracomunitarias y la categoría con más peso porcentual es «Otros», con un 28,4\% (es decir, no se informa de la nacionalidad de uno de cada tres reclusos extranjeros).
} 
Lo que jurídicamente se han definido como garantías para la presencia del imputado en el juicio, o para que no se dé una fuga del territorio nacional durante el disfrute de la libertad condicional o de algún permiso de salida, no se dan de manera general en el colectivo de las personas extranjeras. En concreto, la falta de «arraigo» y una red informal de acogida, unido a posibilidades de inserción laboral regularizada, perjudican sistemáticamente a un conjunto de personas que no encaja en un modelo de cárcel pensada para un preso nacional y masculino (Bodelón González, 2006: 219).

Normativamente, la cárcel parte de un modelo de ciudadano que tiene familia, casa y trabajo. En fin, una trayectoria vital que es poco frecuente en las personas migrantes (Brandariz, 2011: 110). Si un ciudadano extranjero tiene su familia en el país de origen, no reúne los requisitos para contar con una red de apoyo de cara a la salida de prisión, salvo que cuente con el apoyo de alguna asociación (ver Sagredo López, 2000). De igual manera, la falta de una casa, o incluso de un contrato de alquiler previo al encierro en el caso de los extranjeros no migrantes, refuerza la "falta de arraigo", crucial para el decreto de prisión provisional y la concesión de libertad condicional. Si, además, se le junta la inexistencia de una vida laboral continuada o la prohibición legal de trabajar una vez se ha cumplido la condena de prisión, las perspectivas de reinserción social son insuficientes para el sistema penal.

La discriminación que sufren los extranjeros en esta forma de penalización dura, por lo tanto, es el resultado de una ausencia de políticas que adapten las estructuras y las instituciones penitenciarias a las nuevas características de las personas que habitan el país. Las personas migrantes son perjudicadas por unos criterios legales que definen qué es un ciudadano de confianza y que fueron ideados cuando las condiciones de acceso a esos recursos era distinta. Estos criterios no se han actualizado a la realidad económica y social del país, por lo que están penalizando especialmente a las fracciones sociales que se encuentran a la vanguardia de la precariedad y la desprotección social, de entre los cuales destacan las personas que emigran a España. Así mismo, no puede pasarse por alto que el proceso social por el cual los migrantes se ven tan afectados por la precariedad es, en parte, el resultado de las políticas activas de extranjería, que dificultan la integración y el acceso a derechos y facilitan una inserción laboral coaccionada. A pesar de que el tamaño de la red social es importante a la hora 
de paliar los efectos de esta vulnerabilidad, el aspecto económico continúa siendo el más importante (Martínez de Ibarreta, Redondo y Rúa, 2011: 84, 81), por lo que su lugar en el mercado laboral sigue siendo determinante.

Mención aparte merece el hecho de que España es una gran puerta de entrada a Europa para las drogas. En este sentido, la especificidad del caso español frente a otros países europeos ha de ser tenida en cuenta. Primero, porque impide de una manera significativa identificar al colectivo extranjero en prisión con el colectivo migrante y, segundo, eso explica el gran porcentaje de extranjeros y extranjeras ${ }^{6}$ condenados por delitos contra la salud pública.

\section{EFECTOS DE LA PENALIZACIÓN DE LOS MIGRANTES}

Más allá de la irrupción de la penalidad en las biografías migrantes, estos procesos tienen algunas consecuencias de carácter social. La literatura sobre la penalización de migrantes en países de la Unión Europea ha señalado de manera clara e insistente las funciones materiales que ésta cumple. De una manera más puntual y somera, también se ha señalado que cumple una función simbólica en la construcción de la UE. A continuación se explicarán los primeros y, posteriormente, se espera desarrollar algo más el análisis simbólico.

\section{La creación de un ejército de reserva postfordista}

Los análisis teóricos del fenómeno migratorio y su inclusión subordinada mediante la construcción de una ciudadanía de segunda y la amenaza constante del sistema penal se han centrado, principalmente, en la relación entre la penalización de los migrantes

6 El porcentaje de mujeres encerradas por portar sustancias ilegales es mayor por la feminización de una de las partes más precarias del proceso de tráfico de drogas a escala internacional: hacer de «mula». Se reproducen aquí también estructuras sexistas de dominación y precarización. Ver Bodelón González, 2006: 216-217. 
y mercado laboral. Ésta no se ha entendido como una mera cuestión cuantitativa, como buena parte de la economía política del castigo venía haciendo, sino prestando atención a las transformaciones cualitativas de las condiciones del trabajo y actualizando el desempleo como indicador del mercado de trabajo por otros más apropiados a un tipo de economía postfordista (De Giorgi, [2002]: 80 ), como podría ser la precariedad laboral.

La propia laboralización de la política migratoria (Aparicio Wilhelmi, 2010: 61) ha contribuido a centrar el análisis en la relación con el mercado laboral. De hecho, del análisis de la legislación de extranjería se concluye que son los procesos de construcción de irregularidad los que facilitan las condiciones para la explotación laboral (González Cámara, 2011: 240, 326). La amenaza de penalización provee de mano de obra barata a la economía postfordista (De Giorgi, 2010: 147), ya que les pone en una situación en la que aceptar cualquier tipo de condiciones laborales, por malas que sean, es mejor que caer en la irregularidad. En concreto, las personas migrantes en España suelen trabajar más horas que los españoles y con un salario en torno al 20\% menor. La temporalidad de sus contratos es otro rasgo, al que se suma una alta movilidad y una escasa conflictividad laboral, por miedo al despido (ver Requena, Radl y Salazar, 2011: esp. 339-350).

El principio de menor elegibilidad, que parece funcionar muy bien en este caso, ha sido expandido teniendo en cuenta el escenario internacional. De Giorgi (2006: 114-116) ha utilizado la noción de menor elegibilidad global ( global less eligibility») para señalar que, por un lado, las dinámicas capitalistas occidentales reproducen una mano de obra muy barata en los países pobres, hacia donde llevan sus actividades más peligrosas y contaminantes. Por otro lado, al negar la ciudadanía plena a aquellas personas que finalmente consiguen llegar a los países ricos, se consigue una reproducción de una mano de obra barata. En esta línea, Noelia González ha utilizado la idea de acumulación por desposesión de David Harvey para aplicarlo a la producción estatal de un tipo de mano de obra que se caracteriza por no poder organizarse ni laboral ni políticamente y seguir permitiendo el proceso de acumulación capitalista. Así se estarían reproduciendo relaciones centro-periferia dentro de los propios países europeos (González Cámara, 2012: 563-569). 


\section{La construcción de la identidad europea y el lugar del Estado- nación}

A nivel simbólico, se ha señalado que el proceso de «securitización» de la UE es importante para la construcción de la nueva identidad europea, ya que organizar las relaciones sociales como relaciones de seguridad provee de una visión concreta de qué es ser europeo (Loader, 2002: 135). En él, los migrantes serían clave en la construcción de la alteridad, del «otro», de lo que es «no ser europeo» (Brandariz y Fernández, 2010: 277; González Cámara, 2011: 80; De Genova, 2002: 426; Calavita, 2003: 402).

La penalización de los migrantes contribuye a convertirlos en un referente cultural lleno de significados. Por un lado, se da una criminalización en los discursos políticos con efectos categorizantes entre los migrantes buenos -los que vienen a trabajar- y los malos -los que vienen a delinquir- (no se explica que la única diferencia es que unos consiguen temporal y reversiblemente los requisitos burocráticos para trabajar legalmente y los otros no). La desventaja legal de los migrantes como consecuencia de las leyes de extranjería ayuda también a conformarlos como otro diferente (González Cámara, 2011: 83). Otros autores también han apuntado que esta identificación de los inmigrantes como los enemigos ayuda a aliviar el resentimiento de parte de la ciudadanía (Wacquant, 2006: 95), algo que concuerda con otros trabajos que han mostrado cómo el descontento provocado por el cambio social se fija en grupos «contrarios» o considerados forasteros (Gusfield, 1963: 184).

Durkheim ([1893]: 109) ya señaló la importancia del sistema penal en el fortalecimiento de la cohesión social. Así, un discurso político que asocia inmigración y delincuencia facilita la aprobación de leyes que refuerzan esta imagen como, por ejemplo, la inclusión a nivel europeo de los controles de migración como una cuestión de seguridad semejante a las políticas antiterroristas. La creación legal y política de la irregularidad permite interpretar el fenómeno migratorio como algo indeseado.

Como varios trabajos han señalado ya (ver Garland, [1990], cap. 2), el sistema penal y su actuación comunican significados, y ayudan a conformar categorías. Por ejemplo, el trabajo policial comunica significados relativos al orden, la normalidad, la moralidad, la subjetividad o la autoridad, pero también clasifica y representa a individuos (Loader, 1997: 3), y las redadas racistas que durante años 
han llevado a cabo en la calle, con uniformes y notable visibilidad, contribuye a que los vecinos sientan que hay algo peligroso sucediendo en el barrio, y que lo asocien a la presencia de migrantes. Es más, establece divisiones entre los propios vecinos, distinguiendo entre aquellos que pueden ser parados, y los que no (Ávila Cantos, 2012: 259), lo que, en definitiva, supone diferencias importantes de cara al estatus de las personas y de los grupos. Piénsese, por ejemplo, cómo contribuiría a la imagen de los ejecutivos comunitarios que trabajan en España si cada vez que se pasase por la Castellana se viesen tres furgones de la policía frente al edificio y policías pidiendo documentaciones en sus despachos.

La construcción de los inmigrantes asociada a la delincuencia, que es fruto de su posición social, tiene efectos simbólicos de desconocimiento, por cuanto pasa a ser interpretada como una característica propia del grupo. Este efecto de naturalización, o de adjudicación de características personales a personas distintas pero con posiciones sociales similares, se produce al ignorar el conjunto de dinámicas y relaciones, prácticas y leyes, que crean esta situación de alteridad. Este desconocimiento que permite un conocimiento (los inmigrantes son delincuentes) es parte integrante del proceso (Bourdieu, [1980]: 196), e introduce componentes de violencia simbólica en la conformación de la inmigración española y europea.

Siguiendo a Durkheim, Erikson (1966: 4) entendía que cada vez que el grupo condenaba alguna acción o estilo de vida mediante la activación de sanciones, se renovaban y redefinían las fronteras que constituían al grupo, así como sus valores principales. De hecho, al poner las bases de la desviación, se ayuda a definir las bases de la nueva comunidad (Erikson, 1966: 23, 154). En el proceso de conformación de la «europeidad», al condenar públicamente a quienes no poseen alguna de las nacionalidades de los países miembros y, mediante la irregularidad, al denunciar a quienes no trabajan de manera legal, se ayuda a definir qué significa ser europeo: esto es, haber nacido en Europa y trabajar (aunque sea en situaciones precarias que hubieran sido ilegales 30 años atrás). En este sentido, cabría interpretar la penalización de los migrantes como una acción simbólica, comunicativa, por la cual el Gobierno manda un mensaje de con quién está comprometido (los nacionales), degradando y dificultando el reconocimiento social del otro grupo (los migrantes) (ver Gusfield, 1963: 167, 173, 176). 
Por otro lado, no todo es Unión Europea, sino que, dentro de ella, los Estados-nación tienen que seguir haciéndose valer. Precisamente en un contexto de construcción de entidades políticas supranacionales que podrían apuntar a una crisis del propio concepto de estado-nación, su soberanía parece estar en cuestión, y las políticas migratorias parecen ser el último bastión para que el Estado se muestre fuerte (Dauvergne, 2008: 169, 185; Loader, 2002: 126; Wacquant, 2006: 95). No en vano, se ha señalado acertadamente que "pensar la inmigración es pensar el Estado, y que es "el Estado el que se piensa a sí mismo a través de la inmigración" "(Sayad, [1999]: 386)

Si se atiende a los aspectos simbólicos y materiales, se puede empezar a ver que la exclusión económica de los migrantes no es una consecuencia de la legal, sino que se constituyen y refuerzan mutuamente (González Cámara, 2011: 154). Por ejemplo, la exclusión social y política refuerza la inclusión subordinada, pero esta inclusión subordinada también es la que permite que sigan excluidos políticamente, en cuanto que no se pueden constituir como un colectivo poderoso. De igual manera, los «inmigrantes ilegales» pueden ser objeto del sistema penal en tanto que políticamente se les asocia con conductas ilícitas, pero esta asociación sería harto más difícil si no existiese una inclusión económica subordinada que permite asociar la inmigración con situaciones de precariedad o ilegalidad; en definitiva, con los márgenes de la sociedad. Así, en la práctica, es muy difícil separar los efectos materiales de los simbólicos, a pesar de que analíticamente sea pertinente.

\section{Transformación de subjetividades y conformación de ciudadanos dóciles}

En otra línea teórica, más centrada en la subjetivación del proceso, los efectos de la irregularidad y la deportabilidad a ella asociada se puede identificar como similares a los disciplinarios identificados por Foucault (De Genova, 2002: 429). No en un sentido anatomopolítico directo (ver Foucault, [1975]: 139-174) sino que se basa en el temor. El miedo y la ansiedad que sienten los migrantes irregulares cuando van por la calle (Calavita, 2003: 408) les hace, por un lado, desear acceder a cualquier puesto de 
trabajo que les permita obtener la condición (temporal y condicionada) de ciudadano o ciudadana y, por otro, impiden que hagan un amplio uso del espacio público, condenándolos a la invisibilidad y evitando su articulación como sujeto político. «El poder disciplinario, en efecto, es un poder que, en lugar de sacar y retirar, tiene como función principal la de enderezar conductas (...). No encadena las fuerzas para reducirlas; lo hace de maneras que a la vez pueda multiplicarlas y usarlas» (Foucault, [1975]: 175). Este disciplinamiento no se produce mediante el trabajo paciente y detallado sobre cada cuerpo, sino mediante la expansión de dispositivos securitarios dirigidos al grupo migrante en general. Por seguir con la semántica foucaultiana, más que cuerpos dóciles, este disciplinamiento a través de la deportabilidad tendría como consecuencia la producción de «ciudadanos dóciles».

A su vez, este disciplinamiento se da dentro de políticas migratorias biopolíticas, en las que se asume la imposibilidad de frenar las migraciones internacionales y el Estado se propone gestionarlas. Para ello no trata a individuos concretos sino que se centra en el grupo de los «migrantes», a quienes crea como tal mediante herramientas jurídicas, y para el que tiene unas previsiones. A pesar de posibles contradicciones, es posible entender la coexistencia del poder soberano, disciplinario y biopolítico como un triángulo que varía y en el que existe superposición de las distintas lógicas (Foucault, [2004]: 20). Así, se puede superar la separación neta entre técnicas disciplinarias y biopolíticas que algunos autores han defendido (ver De Giorgi, [2002]: 47, 122), y añadir distintos niveles al análisis. Por ejemplo, se pueden identificar técnicas actuariales en la planificación de la actividad policial encaminada a gestionar la inmigración, pero unas rutinas disciplinarias en el trabajo policial de la calle, siendo muy interesante su articulación, tensión y superposición (ver García García, 2012: 579-583). Así mismo, se puede entender que la inclusión subordinada de los migrantes se produce mediante un miedo disciplinario dentro de un control biopolítico (Brandariz, 2011: 103). Esta corriente se muestra especialmente pertinente para su incorporación en estudios cualitativos que lidien con las rutinas y experiencias de la población migrante, habida cuenta de que los propios migrantes pueden haber naturalizado estos procesos $\mathrm{y}$ verlos como normales, o justificados. 


\section{CONCLUSIONES}

En el presente artículo se han analizado las principales formas en las que el sistema penal actúa sobre los extranjeros, con especial atención a la deportabilidad derivada de las leyes de extranjería y a su encierro durante un tiempo mayor en las cárceles. Se pretende así mostrar la pertinencia de prestar atención a los mecanismos punitivos para comprender mejor la situación de la población migrante en España, tanto en el mercado laboral, como en su significado social como grupo, como en la influencia de sus rutinas diarias.

La penalización de los migrantes es el resultado de múltiples lógicas y contradicciones que se dan dentro del campo burocrático nacional y europeo, y entre ellos. A pesar de la lógica expuesta a lo largo del capítulo, su desarrollo e implementación no ha sido unívoco ni exento de contradicciones. Por ejemplo, es fácil encontrar un discurso excluyente y criminalizador desde el Ministerio del Interior, y discursos y políticas integradoras (cuestionables, por supuesto) desde el Ministerio de Empleo y Seguridad Social (el cual contiene la Secretaría de Inmigración y Emigración, significativamente). A pesar de que el discurso securitario parece tener mayor fuerza que el integrador (Brandariz, 2011: 56), aún sigue siendo posible distinguir políticas de control con políticas de integración, y políticas comunitarias con políticas nacionales (Agrela, 2002: 102), con exigencias e intereses que a menudo son distintos.

Las leyes de extranjería, y su aplicación, enmarcan la comprensión de las personas, de manera directa con los migrantes, e indirecta por una redefinición de la ciudadanía, como meros ingredientes de un proceso económico (Dauvergne, 2008: 25). Proceso económico transnacional que se encarna en la figura del migrante, y que muestra las diferencias entre la internacionalización de los capitales y de la mano de obra. En este sentido, la situación de los migrantes está muy vinculada a la precariedad característica del neoliberalismo, y es que el engarzamiento entre políticas activas de extranjería y políticas penales pasivas, que no adecúan sus requisitos normativos -concebidos bajo el paradigma keynesianista- a la situación actual del país, los deja en una posición particularmente difícil en los procesos de penalización.

Su exclusión de la ciudadanía les priva de capital económico, simbólico (prestigio grupal) y social (poder relacional) (Alonso, 2007: 103, no obstante, ver Martín Pérez, 2004). Esta privación les deja 
en una situación en la que el sistema penal se ceba especialmente con ellos, como consecuencia de los múltiples momentos en los que éste actúa de manera selectiva. A su vez, esa misma actuación del sistema penal y su asociación con la delincuencia se usan como justificación de la necesidad de las leyes de extranjería, pues se construyen política y mediáticamente como un grupo diferente-que requiere un trato también diferente-.

Por último, a pesar de que la reciente evolución de los procesos de penalización invita a pensar a los extranjeros como los nuevos clientes predilectos de la cárcel, aquí se defiende que la centralidad la siguen ocupando las clases bajas que guardan alguna relación con las drogas (ya sea como vendedores o como consumidores). A falta de una investigación empírica más sutil, parece que el filtro de clase sigue siendo más importante que el de nacionalidad, pues son raros los extranjeros que proceden de países más ricos que España y que están en la cárcel, o cuya identidad es requerida recurrentemente por la policía. Así, de nuevo, se recuerda la interconexión que existe entre distintas instituciones sociales, como se puede ver en las consecuencias que tiene para la población migrante la existencia de un aparato legislativo que impide su inclusión plena en el mercado laboral y su integración social y política, y que termina repercutiendo en una mayor penalización.

\section{BIBLIOGRAFÍA}

Agrela, B. (2002): «La política de inmigración en España: reflexiones sobre la emergencia del discurso de la diferencia cultural», Migraciones Internacionales 1(2), pp. 93-121.

Alonso, L. E. (2007): La crisis de la ciudadanía laboral. Barcelona, Anthropos.

Aparicio Wilhelmi, M. (2010): «Desde los márgenes. Diversidad cultural, democracia e inclusión social», en Salvatore Palidda y José Ángel Brandariz (dirs.), Criminalización racista de los migrantes en Europa, Granada, Comares, pp. 57-77.

Ávila Cantos, D. (2012): El gobierno de la diferencia: de las lógicas de gestión de lo social, Tesis doctoral, UCM.

BARATTA, F. (2006): «Inmigración y criminalización en los medios de comunicación», en Roberto Bergalli (coord.), Flujos migratorios y su (des)control. Puntos de vista pluridisciplinarios. Barcelona, Anthropos, pp. 261-280. 
Bескетт, K. (1997): Making crime pay: law and order in contemporary American politics. New York, Oxford University Press.

Bodelón GonzÁlez, E. (2006): «La punición de las mujeres inmigrantes en el sistema de justicia penal español», en Roberto Bergalli (coord.), Flujos migratorios y su (des)control. Puntos de vista pluridisciplinarios. Barcelona, Anthropos, pp. 201-227.

Bourdieu, P. [1980]: El sentido práctico. Madrid, Siglo XXI. 2008.

BRANDARIz, J. Á. (2011): Sistema penal y control de los migrantes. Gramática del migrante como infractor penal. Granada, Comares.

Brandariz, J. Á. y Fernández, C. (2010): «La construcción de los migrantes como categoría de riesgo para el sistema penal español», en Salvatore Palidda y José Ángel Brandariz (dirs.), Criminalización racista de los migrantes en Europa. Granada, Comares. Pp. 271-289.

CACHón, L. (2002): «La formación de la «España inmigrante»: Mercado y ciudadanía», Revista Española de Investigaciones Sociológicas 97, pp. 95126.

(2003): «La inmigración en España: los desafíos de la construcción de una nueva sociedad», Migraciones 14, pp. 219-304.

Calavita, K. (1998): "Immigration, law and marginalization in a global economy: notes from Spain», Law \& Society Review 32(3), pp. 529-566.

(2003): «A 'reserve army of delinquents': the criminalization and economic punishment of immigrants in Spain», Punishment \& Society 5(4), pp. 399-413.

Conen, S. [1972]: Folk devils and moral panics. The creation of the Mods and Rockers. London, Routledge, 2011.

Colectivo IOE (2008): Inmigrantes, nuevos ciudadanos. ¿Hacia una España plural e intercultural? Madrid, CECA.

Dauvergne, C. (2008): Making people illegal. What globalization means for migration and law. Cambridge, Cambridge University Press.

De Genova, N. P. (2002): «Migrant «illegality» and deportability in everyday life», Annual Review of Anthropology 31, pp. 419-447.

De Giorgi, A. [2002]: El gobierno de la excedencia. Postfordismo y control de la multitud. Madrid, Traficantes de Sueños, 2006.

(2006): Rethinking the political economy of punishment. Hampshire, Ashgate.

(2010): «Immigration control, post-Fordism, and less eligibility. A materialist critique of the criminalization of immigration across Europe», Punishment \& Society 12(2), pp. 147-167.

Delgado, M. (2006): "Nuevas retóricas para la exclusión social», en Roberto Bergalli (coord.), Flujos migratorios y su (des)control. Puntos de vista pluridisciplinarios. Barcelona, Anthropos, pp. 1-23.

Durkheim, É. [1893]: La división del trabajo social. Buenos Aires, Libertador. 2004. 
ELIAS, N. [1994]: «Ensayo acerca de las relaciones entre establecidos y forasteros», Revista Española de Investigaciones Sociológicas 104(3), pp. 219-251. 2003.

ERIKSON, T. K. (1966): Wayward puritans: a study in the sociology of deviance. New York, John Wiley \& sons.

Fernández Bessa, C. (2015): El dispositiu de deportació. Anàlisi criminológica de la detenció, internament $i$ expulsió d'immigrants en el context espanyol. Tesis doctoral, UB.

Fiscalía (2008): Memoria de la Fiscalía General del Estado. Consultada en www.fiscal.es

Foucault, M. [1975]: Vigilar y castigar: Nacimiento de la prisión. Madrid, Siglo XXI, 1979. [2004]: Seguridad, territorio, población. Madrid, Akal, 2008.

GARCía AÑón, J. (dir.) (2013): Identificación policial por perfil étnico en España. Informe sobre experiencias y actitudes en relación con las actuaciones policiales. Valencia, Tirant lo Blanch.

García EsPaña, E. (2007): «Extranjeros presos y reinserción: un reto del siglo XXI», en Ana Isabel Cerezo Domínguez y Elisa García España (coords.), La prisión en España: una perspectiva criminológica. Granada, Comares, pp. 101-134.

García España, E., J. Becerra Muñoz y A. Aguilar Conde (2012): Realidad y política penitenciarias. Málaga, Instituto Andaluz Interuniversitario de Criminología.

García García, S. (2012): «Dispositivo securitario en un espacio barrial. La práctica policial de los controles de identidad», Arbor 188(755), pp. 573-590.

GARLAND, D. [1990]: Castigo y sociedad moderna: un estudio de teoría social. México, Siglo XXI, 1999.

Gil Araúso, S. (2005): «Muros alrededor de «el Muro». Prácticas y discursos en torno a la inmigración en el proceso de construcción de la política migratoria comunitaria» en María Teresa Martín Palomo, María Jesús Miranda y Cristina Vega Solís (coords.), Delitos y Fronteras. Mujeres Extranjeras en prisión. Madrid; Instituto de Investigaciones Feministas de la UCM, pp. 113-138.

GonzÁlez CÁmARA, N. (2011): Migrantes, procesos de irregularización y lógicas de acumulación y exclusión. Un estudio desde la filosofía politica. Tesis doctoral, UPF.

(2012): «Desposesión y producción de irregularidad: la gestión de las migraciones en la era del neoliberalismo», Arbor 188 (755), 559-572.

GonzÁlez SÁnchez, I. (2012): «La cárcel en España: mediciones y condiciones del encarcelamiento en el siglo XXI», Revista de Derecho Penal y Criminología 8, pp. 351-402.

Gusfield, J. R. [1963]: Symbolic crusade. Status politics and the American Temperance movement. Urbana, University of Illinois Press, 1969. 
Hall, S., Critcher, C., Jefferson, T., Clarke, J. y Roberts, B. (1978): Policing the crisis. Mugging, the State, and law and order. London, Macmillan.

Huysmans, J. (2000): "The European Union and the securitization of migration», Journal of Common Market Studies 38(5), pp. 751-777.

Igartua, J. J., Muñiz, C. y Cheng, L. (2005): «La inmigración en la prensa española. Aportaciones empíricas y metodológicas desde la teoría del encuadre noticioso», Migraciones 17, pp. 143-181.

IzQuiERdo, A. (1996): La inmigración inesperada. La población extranjera en España. Madrid, Trotta.

LOADER, I. (1997): "Policing and the social: questions of symbolic power», British Journal of Sociology 48(1), pp. 1-18.

(2002): "Policing, securitization and democratization in Europe», Criminal Justice 2(2), pp. 125-153.

Martín Pérez, A. (2004): «Las asociaciones de inmigrantes en el debate sobre las nuevas formas de participación política y de ciudadanía», Migraciones 15, pp. 113-143.

Martínez de Ibarreta, C., Redondo, R. y Rúa, A. (2011): «Impacto de las redes sociales de apoyo sobre la vulnerabilidad de los inmigrantes. Un análisis del caso español», Migraciones 29, pp. 61-94.

Martínez Escamilla, M. (2011): «Los centros de internamiento para extranjeros: régimen jurídico y realidad», Estudios Jurídicos.

Martínez Lirola, M. (ed.) (2008): Inmigración, discurso y medios de comunicación. Alicante, Instituto Alicantino de Cultura.

Monclús Masó, M. (2006): «La discriminación de los inmigrantes en el sistema penal español», en Roberto Bergalli (coord.), Flujos migratorios y su (des)control. Puntos de vista pluridisciplinarios. Barcelona, Anthropos, pp. 159-200.

Rechea Alberola, C., Fernández Molina, E. y Benítez Jiménez, Ma J. (2005): «La visión de la seguridad en prensa. Una valoración del tratamiento que realizan los medios de prensa sobre la delincuencia y la inseguridad ciudadana» en http://documentostics.com/component/option,com_ docman/task,doc_view/gid,857/

Requena, M., RadL, J. y SALAZAR, L. (2011): «Estratificación y clases sociales», en VV.AA., Informe España 2011. Una interpretación de la realidad social. Madrid, Fundación Encuentro, pp. 301-366.

SAGredo López, L. (2000): «Programa de reinserción de extranjeros presos mediante la utilización de un piso de acogida: experiencia en la asociación «Málaga Acoge»», Migraciones 7, pp. 281-290.

SAYAD, A. [1999]: La doble ausencia. De las ilusiones del emigrado a los padecimientos del inmigrado. Barcelona, Anthropos, 2010.

Serrano Gómez, A., Vázquez, C., Serrano, M. D., luaces, A. I., Serrano, M. I., Fernández, T. y García, J. (2007): «Tendencias de la criminalidad y percepción social de la inseguridad ciudadana en España y la Unión 
Europea», en Alfonso Serrano Gómez (dir.) y Carlos Vázquez González (coord.) (2007), Tendencias de la criminalidad y percepción social de la inseguridad ciudadana en España y la Unión Europea. Madrid, Edisofer, pp. 17-203.

Silveira Gorski, H. C. (2010): «Estados expulsores y semipersonas en la Unión Europea», en Cristina Fernández Bessa, Héctor Silveira Gorski, Gabriela Rodríguez Fernández e Iñaki Rivera Beiras (eds.), Contornos bélicos del Estado securitario. Control de la vida y procesos de exclusión social. Barcelona, Anthropos, pp. 133-158.

Silveira Gorski, H. C. e Rivera Beiras, I. (2009): «La biopolítica contemporánea ante los flujos migratorios y el universo carcelario. Una reflexión sobre el regreso de los «campos» en Europa», en Ignacio Mendiola (ed.), Rastros y rostros de la biopolítica, Barcelona, Anthropos, pp. 271-292.

Villalobos Molina, C. (2005): "Análisis de la representación del inmigrante delincuente en la prensa española de referencia. Obstáculos para la comunicación intercultural», Redes.com 2, pp. 153-166.

Wacouant, L., (2006): «Penalization, depoliticization, racialization: on the over-incarceration of immigrants in the European Union», en Sarah Armstrong y Lesley McAra (eds.), Perspectives on punishment: the contours of control: new. Oxford, Clarendon Press, pp. 83-100.

Wagman, D. (2005): "Población extranjera y minorías étnicas», en César Manzanos (coord.), Servicios sociales y cárcel. Alternativas a la actual cultura punitiva. Vitoria: Salhaketa, pp. 83-99.

Zuloaga, L. (2011): La priorización de la inseguridad ciudadana como problema. Las claves de su presencia en la agenda pública. Tesis doctoral, UPNA. 
